Bull. Astron. Belgrade № 153 (1996), $29-34$

UDC 524.882

Original scientific paper

\title{
BOSE INSTABILITY IN KERR BLACK HOLES
}

\author{
A. B. Gaina \\ ERGO.,2 Deleanu str., ap.146, Chişinău 277050, Republic of Moldova \\ phone (3732)639114, e-mail: acadm@mdearn.cri.md
}

(Received: December 20, 1995)

\begin{abstract}
SUMMARY: Bose instability in rotating (Kerr) black holes (BH's) consists in exponential increase in time of small perturbations of Bose mass fields, corresponding to superradiative, quasi bound levels. The minimal time of dumping of the angular momentum on the $2 P$ envelope is much less than the time of dumping of the angular momentum by superradiation for primordial BH's when the mass of the particles $m<<\frac{M_{P l}^{2}}{M}$. Very fast dumping of the angular momentum occures when $0.46 \geq \frac{m M}{M_{P l}^{2}} \geq 0.203$ (for $\pi^{0}$ ), $0.353(\eta), .0 .065\left(D^{0}\right)$. Electrically charged particles cannot develop Bose instability due to the ionization of bound levels by electromagnetic radiation emitted by the $\mathrm{BH}$ itself.

The neutral particles produce $\gamma$-bursts of energies 67.5, 274.5, 932 Mev correspondingly. The duration of bursts is $1.26 \cdot 10^{-17} \mathrm{~s}\left(\pi^{0}\right), 2.99 \cdot 10^{-18}$ $\mathrm{s}(\eta), 8.55 \cdot 10^{-19} \mathrm{~s}\left(D^{0}\right)$. The radiated energies are $1.20 \cdot 10^{35} \mathrm{erg}, 8.67 \cdot 10^{34} \mathrm{erg}$, $8.55 \cdot 10^{33} \mathrm{erg}$, corresponding to powers of the order of magnitude $10^{52} \frac{\mathrm{erg}}{\mathrm{s}}$. Other consequences for BH's evaporation are discussed.
\end{abstract}

\section{INTRODUCTION}

Bose instability of rotating Black Holes (Kerr $\mathrm{BH}$ 's) is related with an exponential increase in time of small perturbations of a test mass field, corresponding to superradiative quasibound states with energies:

$$
E \leq \min \left\{\mu c^{2}, \hbar m \Omega_{H}\right\}
$$

where $\mu$ and $E$ are respectively the rest mass and energy of the particles, $m$ is the projection of the momentum on the BH's axis, $M$ and $J=M a c$ are mass and angular momentum of the $\mathrm{BH}$ and the angular velocity of the $\mathrm{BH}$ is written as

$$
\Omega_{H}=\frac{a c^{3}}{2 G M r_{+}}
$$

where

$$
r_{+}=G M / c^{2}+\left(G^{2} M^{2} / c^{4}-a^{2}\right)^{\frac{1}{2}} .
$$

On the level of a second quantized quantum field theory (in brief QFT) this corresponds to the occurrence of spontaneous and induced particles creation proce- 
sses on quasi bound superradiative levels. Only spontaneous generation of fermions may occur due to Dirac exclusion principle, but bosons may accumulate on such levels by induction (or stimulation). On the level of Klein-Gordon,Dirac and other similar QF equations this corresponds to the fact that $s=\frac{1}{2}, \frac{3}{2}, \ldots$ mass equations support only dumping (Gaina et al. 1980) while the $s=0,1,2, .$. mass equation may change the sign of the imaginary part of the energy (Ternov et al. 1978):

$$
\begin{aligned}
& E=E_{n l m}^{(0)}-i \gamma_{n l m}, \\
& E^{(0)} \equiv \operatorname{Re} E<\mu c^{2},
\end{aligned}
$$

$\gamma \equiv \operatorname{Im} E=\left\{\begin{array}{r}>0, \text { for } s=\frac{1}{2}, \frac{3}{2}, \ldots ; \\ >0, \text { for } s=0,1, \ldots \text { and } E^{(0)}>\hbar m \Omega_{H} ; \\ \leq 0, \text { for } s=0,1, \ldots \text { and } E^{(0)} \leq \hbar m \Omega_{H} .\end{array}\right.$

In other words, bosons supports self-stimulated generation (and in consequence -accumulation) on quasi-bound superradiative states (1) in which the wave function increase as $\Phi \sim e^{\lambda t}$, where $\lambda=-\gamma$, for $E^{0}$ $\leq \hbar m \Omega_{H}$ and the number of particles and the energy density increase as:

$$
\begin{aligned}
& N=\frac{1}{2} i \int\left\{\Phi^{*}\left(\partial^{0} \Phi\right)-\Phi\left(\partial^{0} \Phi\right)^{*}\right\} \sqrt{-g} d^{3} x \sim e^{2 \lambda t} C \\
& \mathcal{E}=\int k_{(t)}^{\nu} T_{\cdot \nu}^{0} \sqrt{-g} d^{3} x=\int T_{.0}^{0} \sqrt{-g} d^{3} x \sim e^{2 \lambda t},
\end{aligned}
$$

where $k_{(t)}^{\nu}=\delta_{t}^{\nu}$ is time like Killing vector of the Kerr metrics. One could show by an alternative way that the probability of the transition of a system $(\mathrm{BH}+$ bosons) from an initial state $\mid N_{\vec{k}}, 0>$ with $N_{\vec{k}}$ bosons with quantum number $\vec{k}$ and 0 antibosons into a final state $\mid N_{\vec{k}}+1,1>$ with $N \vec{k}+1$ bosons and 1 antiboson will be proportional to the square of the matrix element

$$
\left|<0, n_{k}\right| T_{.0}^{0}\left|n_{k}+1,1>\right|^{2}=|c|^{2}\left(N_{k}+1\right) .
$$

When $N_{\vec{k}}=0$, this is just the probability of a spontaneous generation of a pair boson-antiboson from which one particle localized on quasibound state and other inside the BH. Otherwise (6) gives the probability of self-stimulated generation of pairs.

So, one could take into consideration the following equations for the number of particles on the superradiative levels, mass, angular momentum variations of a BH (Gaina, 1989):

$$
\frac{d N_{n l m}}{d t}=\lambda_{n l m}\left(N_{n l m}+1\right)
$$

$$
\begin{gathered}
\frac{d\left(M c^{2}\right)}{d t}=-\sum_{n l m} \lambda_{n l m} E_{n l m}^{(0)}\left(N_{n l m}+1\right), \\
\frac{d J}{d t}=-\sum_{n l m} \lambda_{n l m} \hbar m\left(N_{n l m}+1\right) .
\end{gathered}
$$

Equation (7) gives the number of particles on the quasilevel with quantum numbers $n \equiv 1+l+n_{r}, l$, $m\left(n_{r}=0,1,2, \ldots ; l=0,1,2, \ldots\right)$ for scalar bosons. Generally, equations (7)-(9) are nonlinear, admitting solutions only in very special cases.

\section{BOSE INSTABILITY IN KERR BH'S}

Let us restrict ourselves here to examination only of scalar bosons, as the solutions for the vector bosons and other boson mass fields are still unknown in Kerr backgrounds.

As it was shown (Gaina, 1989) only the case

$$
\mu M \preceq M_{P l}^{2} \equiv \frac{\hbar c}{G}
$$

is of interest, if one excludes the case of very large $\mu \rightarrow M_{P l}$. The probabilities of particles generation were calculated in Gaina et al. (1980) (see also Detweiler, 1980; Gaina and Kochorbe, 1987). The main contribution to the change of mass and angular momentum of the $\mathrm{BH}$ gives rise to the generation and accumulation of particles on the $2 \mathrm{P}$ level. The dynamic equations for the number of particles and angular momentum are (we use below the system of units $c=\hbar=G=1$ ):

$$
\begin{gathered}
\frac{d N_{n p}}{d t}=\lambda_{n p}\left(N_{n p}+1\right) ; \\
\frac{d J}{d t} \simeq-\frac{d N_{2 p}}{d t}
\end{gathered}
$$

while the mass change is negligible.

By using the law of conservation of total angular momentum $J=J_{0}-\sum_{n} N_{n p}$ in the system $\mathrm{BH}+$ bosons we obtain the law of variation of the number of particles and angular momentum of the $\mathrm{BH}$ in explicit form:

$$
\begin{gathered}
N_{n p}=J_{0}^{\prime} \frac{1-\exp \left[-\left(J_{0}^{\prime}+1\right) \mu^{9} M^{6} t / 48\right]}{1+J_{0}^{\prime} \exp \left[-\left(J_{0}^{\prime}+1\right) \mu^{9} M^{6} t / 48\right]} \\
J=J_{0}-N_{2 p}
\end{gathered}
$$

where

$$
J_{o}^{\prime}=J_{0}-J_{s t}
$$


$J_{s t}$ being the $\mathrm{BH}$ angular momentum at which superradiance at the given level stops. The exact value of $J_{s t}$ is :

$$
J_{s t}=\frac{4 E^{(0)} M^{3} m}{m^{2}+4\left(E^{(0)}\right)^{2} M^{2}},
$$

while for the case $\mu M<<1$ one obtains:

$$
J_{s t} \simeq 4 \mu M^{3}<<M^{2} .
$$

Note that the time of dumping of the angular momentum of the $\mathrm{BH}$ into the levels is

$$
\tau_{J} \approx 48 t_{P l}\left(\frac{M_{P l}}{\mu}\right)^{3}\left(\frac{M_{P l}^{2}}{\mu M}\right)^{6} \frac{\ln \left(J_{0}-J_{s t}+1\right)}{\left(J_{0}-J_{s t}\right)} ;
$$

which approximately equals

$$
\tau_{J} \approx 96 t_{P l}\left(\frac{M_{P l}}{\mu}\right)\left(\frac{M_{P l}^{2}}{\mu M}\right)^{8} \ln \frac{M}{M_{P l}}
$$

when $\mu M \ll M_{P l}^{2}$. The mass of the envelope of bosons on $2 P$ state is $\triangle M=M_{0}-M_{s t} \approx \mu N_{2 p} \approx$ $\mu J_{0}^{\prime} \approx \mu\left(J_{0}-J_{s t}\right) \approx \mu M a_{0}$. It will be much less than the mass of the BH itself if $\mu M<<M_{P l}^{2}$.

The discussion of other details of the dumping of the angular momentum of the $\mathrm{BH}$, caused by Bose instability is given in Gaina (1989).

The time of loss of the angular momentum of a rotating black hole by superrradiation (see Zel'dovitch, 1971) is

$$
\tau_{\text {superrad }} \sim 8 \pi e^{\xi}\left(\frac{M}{M_{P l}}\right)^{3} t_{P l},
$$

where $\xi$ is of order unity. Then, the ratio

$$
\frac{\tau_{\text {superrad }}}{\tau_{J}}=\frac{\pi}{12} e^{\xi}\left(\frac{M}{M_{P l}}\right)^{2}\left(\frac{M \mu}{M_{P l}^{2}}\right)^{9} \ln ^{-1} \frac{M}{M_{P l}}
$$

may be much greater than unity if $M \gg M_{P l}$. We do not now consider the cases $\mu \preceq M_{P l}, M \succeq M_{P l}$ and $\mu M \sim M_{P l}^{2}$. For the latest one we can give some estimations based on analytical approaches developed in Gaina et al. (1980), Ternov et al. (1978), Gaina (1989) and Zouros and Eardley (1979), while an exact treatment should be given numerically.

The probability of pair production for the case $\mu M \gg M_{P l}^{2}$ was calculated by Zouros and Eardley (1979) for scalar bosons and improved by Gaina (1989) . Tunneling probability near the threshold of pair production for $E \preceq \mu, a \rightarrow M$ (but $a \neq M$ ), and $l-m \approx\left|m-m_{0}\right|<<m_{0}=\mu / \Omega_{H}$ has the form (Gaina, 1989).

$$
\begin{aligned}
& \lambda_{m}(a)=10^{-7} \frac{\operatorname{sign}\left(m-m_{0}\right)}{M} \\
& \exp \left\{-2 \pi \mu M\left(2 \sqrt{1-\frac{m-m_{0}}{m_{0 \sqrt{1-\frac{a^{2}}{M^{2}}}}}}-\sqrt{2}\right)\right\} .
\end{aligned}
$$

Here we omit the weaker dependence on the orbital quantum number and the particle energy. As $m \rightarrow m_{0}$ the exponent in eq. (5) changes into the result in Zouros and Eardley (1979) to within a factor of two in the exponent. The corresponding time of relaxation (dumping) of angular momentum for an extremely rapidly rotating black hole with unfilled levels is less than the age of the universe for BHs with masses $\mu M \preceq(23 \div 26) M_{P l}^{2}$. The characteristic range of variation of the specific angular momentum of the $\mathrm{BH}$ is $0.6 \preceq a / M<1$.

One should emphasize that thermal effects will be small if the temperature of $\mathrm{BH}$ : $k T_{B H}=\sqrt{1-a^{2} / M^{2}} / 4 \pi r_{t}<<E^{(0)} \approx \mu c^{2}$. From this it is easy to obtain the criterion for macroscopic tunneling:

$$
\sqrt{1-\left(a c^{2} / G M\right)^{2}}<<4 \pi \mu M / M_{P l}^{2} .
$$

It can be satisfied easily for rapidly rotating $\left(a c^{2} \rightarrow G M\right)$ or macroscopic $\left(\mu M>M_{P l}^{2}\right)$ back holes.

\section{THE ENERGETIC SPECTRUM OF QUASI BOUND LEVELS}

There are very different energy spectra in the long wave length $\left(\mu M<<M_{P l}^{2}\right.$, or $\left.r_{+}<<\lambda_{c}^{\prime}\right)$ and short wave length $\left(\mu M \gg M_{P l}^{2}\right.$, or $\left.r_{+} \gg \lambda_{c}^{\prime}\right)$ limits. In the first case we have a full hydrogenlike spectrum for $a=0$

$$
\frac{E_{n}^{0}}{\mu}=1-\frac{\mu^{2} M^{2}}{2 n^{2}}
$$

$\mathrm{S}$ quasibound levels appear for $\mu M \preceq 0.25 M_{P l}^{2}, \mathrm{P}$ quasibound levels appear for $\mu M \preceq 0,46 M_{P l}^{2}$ (see Zouros and Eardley, 1979), D quasibound levels appear for $\mu M \preceq 0,74 M_{P l}^{2}$ and so on, $n l$ quasilevel appear for $\mu M \preceq \frac{\sqrt{3}}{6} M_{P l}^{2}$ if $l \gg 1$ (quasiclassical limit). Such a criterion for the Kerr metrics it is still unknown. The extremely rotating Kerr BH were examined in Gaina and Zaslavskii (1992). It was shown that the marginally stable corotating orbit is dumped for Klein-Gordon particles. 
However, it is known (Gaina, 1989a) that the spectrum (24) is a good approximation also for Kerr metric if

$$
\mu M<<l+\frac{1}{2} .
$$

So, one could expect that the criterion for the existence of a $2 \mathrm{P}$ and $3 \mathrm{D}$ quasibound levels is roughly the same as for a Shwarzshild BH.

\section{ELEMENTARY PARTICLES AND THE MASSES RANGES FOR BOSE INSTABILITY}

Assuming $\mu M \approx 0.45$ one derives from eq. (18) the minimal dumping time of the angular momentum for an extremely rotating $\mathrm{BH}$ :

$$
\tau_{J(\min )}=5.7 \cdot 10^{4} \mu^{-1} \ln \left(\frac{M}{M_{P l}}\right) .
$$

By taking into account the time life of the most of mesons $\tau_{L}<10^{-8}$ one obtains that boson instability cannot develop for BHs with masses $M>5 M_{P l}^{2} / \mu_{\pi}=3.8 \cdot 10^{16} g$. If we assume, however, that boson instability occurs for neutrino pairs (assuming the neutrino to have mass) with a characteristic time determined by equation (26), we obtain an upper limit on the mass of a $\mathrm{BH}$ subjected to boson instability: $M<2.4 \cdot 10^{23} \mathrm{~g}$. For known bosons the masses ranges for black holes subjected to Bose instability are given in Table 1.

It is easy to see that the bosonic instability cannot develop for $\eta$-meson, $W^{ \pm}$and $Z^{0}$ due to very short lifetime. On the other hand one should give a rigorous treatment of $\eta$ decay near the horizon of the black hole which could warrant our expectations for accumulations of $\eta$ mesons. One must take into account also that estimations for the upper limit mass of the $\mathrm{BH}$ subjected to vector instability were made on the basis of scalar equation and the actual value of the $\tau_{J}$ may be less for $W^{ \pm}$and $Z^{0}$.

Table 1. Masses Ranges for the Known Bosons

$\begin{array}{lrrrc}\text { Particle } & \frac{\text { Life time }}{\tau_{\mathrm{L}}(\mathrm{s})} & \frac{\text { Low limit }}{\text { mass }(\mathrm{g})} & \frac{\text { Upper limit }}{\text { mass }(\mathrm{g})} & \frac{\text { Mass of the particles }}{(\mathrm{Mev})} \\ \pi^{ \pm} & 2.6 \cdot 10^{-8} & 5.8 \cdot 10^{13} & 8.5 \cdot 10^{14} & 140 \\ \pi^{0} & 0.8 \cdot 10^{-16} & 7.0 \cdot 10^{14} & 8.85 \cdot 10^{14} & 135 \\ \eta & 2.4 \cdot 10^{-19} & 3.0 \cdot 10^{14} & 2.18 \cdot 10^{14} & 549 \\ K^{0}, \bar{K}^{0} & 10^{-9} & 2.1 \cdot 10^{13} & 2.4 \cdot 10^{14} & 498 \\ D^{0} & 5 \cdot 10^{-13} & 1.6 \cdot 10^{13} & 6.42 \cdot 10^{13} & 1864 \\ D^{ \pm} & 10^{-12} & 1.5 \cdot 10^{13} & 6.4 \cdot 10^{13} & 1869 \\ F^{ \pm} & 2 \cdot 10^{-13} & 9.4 \cdot 10^{12} & 5.9 \cdot 10^{13} & 2020 \\ W^{ \pm} & 3 \cdot 10^{-25} & 4.8 \cdot 10^{12} & 1.2 \cdot 10^{12} & 83 \cdot 10^{3} \\ Z^{0} & -/ /- & 4.2 \cdot 10^{12} & 1.08 \cdot 10^{12} & 93 \cdot 10^{3}\end{array}$

\section{STOPPING THE INSTABILITY FOR ELECTRICALLY CHARGED PARTICLES. ELECTROMAGNETIC TRANSITIONS AND PHOTOIONIZATION}

Of course, we do not take into account the annihilation of $\pi^{ \pm}, K^{ \pm}, D^{ \pm}$and $F^{ \pm}$during their generation and accumulation near the Black Hole. Particles of opposite charges may annihilate rapidly during their generation. But one must take into account the influence of a strong gravitational field near the horizon of a black hole.

Let us assume that electrically charged particles and their antiparticles could accumulate on quasilevels, for instance, on 2P quasibound level in the field of an highly rotating $\mathrm{BH}(a \rightarrow M)$ of mass $M \preceq 0.45 M_{P l}^{2} / \mu$, i.e. near the upper limit of Bose instability. In this case one has 3 processes which can stop the instability: i) electromagnetic transitions $2 p \rightarrow 1 s$, or other transitions on nonsuperradiative levels; ii) annihilation of particles into two fotons $\left(\pi^{+}+\pi^{-} \rightarrow 2 \gamma, K^{+}+K^{-} \rightarrow 2 \gamma\right.$, and so ones);

iii) photoionization of bound levels by the electromagnetic radiation emitted by the $\mathrm{BH}$ itself.

The equation which governs the number of particles on $2 \mathrm{P}$ level is:

$$
\begin{gathered}
\frac{d N_{2 p}}{d t}=\lambda_{2 p}\left(N_{2 p}+1\right)-W_{2 p \rightarrow 1 s} N_{2 p}- \\
W_{a n n} N_{2 p}-W_{i o n} N_{2 p}^{2} .
\end{gathered}
$$


It is not difficult to calculate the probability of normal dipole transitions $2 p \rightarrow 1 s$ in the field of a such black hole assuming, that a hydrogenlike spectrum of bound states is realized. One could note that there are also anomalous transitions with $\Delta m=$ 0 which may have the same order of magnitude in the field of an extremely rotating BH (Chizov and Myshenkov, 1991) but we do not examine here such transitions. The probability $W_{2 p \rightarrow 1 s}$ will be:

$$
W_{2 p \rightarrow 1 s}=\left(\frac{2}{3}\right) \alpha \mu(\mu M)^{4} .
$$

Transitions (28) impose further restraints on the masses of BH's supposed to Bose instability:

$$
M \geq^{4} \sqrt{\frac{2^{10} \alpha}{3^{7}}} \frac{M_{P l}^{2}}{\mu}=0.24 \frac{M_{P l}^{2}}{\mu},
$$

that is the actual low limit mass for instability will be greater for $\pi^{ \pm}, D^{ \pm}, F^{ \pm}, K^{ \pm}$.

The total cross section of annihilation of particles of opposite charges on the quasilevels may be also very easily estimated in the nonrelativistic limit:

$$
\sigma_{a n n}=\frac{\alpha^{2}}{2 \mu E^{(0)}} \approx \frac{\pi \alpha^{2}}{2 \mu^{2}} .
$$

Akhiezer and Berestetsky (1981) give an exact formula for the cross section of ionization of $2 \mathrm{P}$ atomic levels. In the case of $\mathrm{N} 2 \mathrm{P}$ electrons one has:

$$
\begin{aligned}
\sigma_{2 p}= & N_{2 p} \frac{2^{10} \pi^{2} \alpha}{9 \mu I_{2 p}}\left(\frac{I_{r p}}{\hbar \omega}\right)^{5}\left(3+8 \frac{I_{r p}}{\hbar \omega}\right) \\
& \frac{e^{-4 \eta \operatorname{arctg} \frac{\eta}{2}}}{1-\exp (-2 \pi \eta)} .
\end{aligned}
$$

In the limit $\hbar \omega \gg I_{r p}$ one has approximately:

$$
\sigma_{2 p} \simeq \frac{2^{8} \alpha \pi}{3 \mu I_{r p}}\left(\frac{I_{r p}}{\omega}\right)^{9 / 2} N_{2 p} .
$$

Adapting this formula for a $\mathrm{BH}$ we obtain the cross section of photoionization of one particle on $2 \mathrm{P}$ level $\left(Z_{\alpha} \rightarrow \mu M / M_{P l}^{2}\right)$ :

$$
\sigma_{2 p}=\frac{\pi \alpha\left(\lambda_{c}^{\prime}\right)^{2}}{12 \sqrt{2}}\left(\frac{\mu}{\omega}\right)^{9 / 2}(\mu M)^{7} N_{2 p} .
$$

An important feature of the cross section (31) is the dependence of the rate of ionization on the number of particles on the level.

Let us calculate now the probability of ionization of one electrically charged $2 \mathrm{P}$ scalar particle by electromagnetic radiation emitted by the $\mathrm{BH}$ itself as a result of superradiance. The probability will be:

$$
W_{r p}^{(i o n)}=\frac{1}{S} \int \frac{d n_{p}}{d t d w} \sigma_{2 p} d w
$$

where

$$
\begin{aligned}
\frac{d n_{p}}{d t d w} & =\frac{1}{2 \pi}<n>=\frac{\Gamma_{1 \omega 1 m p}}{2 \pi}= \\
& =\frac{4}{9} \frac{8 \pi M r_{+}}{2 \pi^{2}} M^{2}\left(\omega-\Omega_{H}\right) \omega^{3}
\end{aligned}
$$

is the number of p-photons emitted by the BH (Akhiezer and Berestetsky, 1981). In the limit $a \rightarrow M$ one has:

$$
\frac{d n_{p}}{d t d w}=\frac{8 M^{3} \omega^{3}}{9 \pi}
$$

After the integration of (32) with $S=a_{0}^{2}=\frac{1}{\mu^{4} M^{2}}$ one has:

$$
W_{2 p}^{(i o n)}=\frac{8 \alpha}{81 \pi} \mu(\mu M)^{11} .
$$

For $\mathrm{N}_{2 p}$ particles localized on $2 \mathrm{P}$ level this formula must be multiplied by $N_{2 p}$. Thus, photoionization is slow compared with dipole transitions for small occupation numbers, but may suppress the last ones for great $N_{2 p}$. It is easy to estimate the number of particles on the $2 \mathrm{P}$ level after the photoionization ignoring the dipole transitions and annihilation of pairs. The equation (29) will have the form:

$$
\frac{d N_{2 p}}{d t}=\lambda_{2 p}\left(N_{2 p}+1\right)-W_{2 p}^{(i o n)} N_{2 p}^{2} .
$$

Assuming $N_{2 p} \gg 1$ one obtains for the equilibrium number of particles:

$$
N_{r p}=\frac{\lambda_{2 p}}{W_{r p}^{(i o n)}}=\frac{81 \pi}{96 \alpha}(\mu M)^{-3},
$$

that is for a $\mathrm{BH}$ with incipient instability $(\mu M \approx 0,45)$ one derives

$$
N_{2 p}=3985 \text {. }
$$

So, photoionization stops efficiently Bose instability for electrically charged mesons $\pi^{ \pm}, K^{ \pm}$, $D^{ \pm}, F^{ \pm}$.

\section{CONCLUSIONS}

From the Table 1 it is easy to see that the bosonic instability cannot develop for $\eta$-meson, $W^{ \pm}$ and $Z^{0}$ due to very short lifetime. On the other hand one should give a rigorous treatment of $\eta$ decay near the horizon of the black hole which could warrant our expectations for accumulations of $\eta$ mesons.

One must take into account also that estimations for the upper limit mass of the $\mathrm{BH}$ subjected to vector instability were made on the basis of scalar equation and the actual value of the $\tau_{J}$ may be less for $W^{ \pm}$ and $Z^{0}$. 
Self stimulated generation and accumulation of bosons in the field of highly rotating black holes (Bose instability) is an efficient mechanism of dropping of angular momentum for primordial black holes. Electrically charged particles cannot accumulate near the black hole due to electromagnetic transitions, annihilations and photoionization. But $\pi^{0}, D^{0}$, $K^{0}$ could rapidly accumulate near black holes and produce after $\gamma$ bursts of powers:

$$
\left(\frac{d E}{d t}\right)_{i n t} \simeq \frac{1}{288} \frac{c^{5}}{G}\left(\frac{\mu M}{M_{P l}^{2}}\right)^{10} \frac{1}{\ln \frac{M}{M_{P l}}},
$$

that is $\simeq 9,5 \cdot 10^{51} \mathrm{erg} / \mathrm{s}$ (for $\pi^{0}$ ), 2.9.10 ${ }^{52} \mathrm{egr} / \mathrm{s}$ (for $\eta$ ), $10^{52} \mathrm{erg} / \mathrm{s}$ (for $\mathrm{D}^{0}$ ), if one assume $\mathrm{BH}$ to be near the threeshold of instability (i.e. $\mu M \approx 0.45 M_{P l}^{2}$ ). This corresponds to effective masses of radiated energies: $133 \mathrm{Mt}$ (for $D^{0}$ ). The energies of $\gamma$-photons radiated will be $67,5 \mathrm{Mev}$ (for $\pi^{0}$ ), 274,5Mev (for $\eta$ ), 932Mev (for $D^{0}$ ).

\section{REFERENCES}

Akhiezer, A. I. and Berestetsky, V. B.: 1981, Quantum Electrodynamimics, Nauka, Moscow.
Chizov, G. A., Myshenkov, O.: 1991, Preprint of the Physics Dept. Moscow State University.

Detweiler, S.: 1980, Phis. Rev., D 22, 2323.

Gaina, A.: 1989, Pis'ma Astron. Zh. 15, 567 [Engl. transl.: Sov. Astron. Lett. 15(3), 567 (1989)].

Gaina, A: 1989a, Quantum Particles in Einstein-Maxwell Fields Stiinta, Chisinau.

Gaina, A. and Kochorbe, F. G.: 1987, Zh. Exp. Teor. Fiz. $92,369$.

Gaina, A., Ternov, I. M. and Chizhov, G. A.: 1980, Izv. Vyssh. Uchebn. Zaved., Fiz. 23, No. 8, 56 [Engl. transl.: Sov. Phys. J. 23, No 8 (1980)].

Gaina, A. and Zaslavskii, O. B.: 1992, Class. Quantum. Grav. 9, 667 .

Starobinsky, A. A. and Churilov, S. M.: 1973, Zh. Exp. Teor. Fiz. 65, 3.

Ternov, I. M., Khalilov, V. R., Chizhov, G. A. and Gaina, A. B.: 1978, Izv. Vyssh. Uchebn. Zaved., Fiz. 21, No. 9, 109 [Engl. transl.: Sov. Phys. J. 21, No. 9 (1980)].

Zel'dovitch, Ya. B.: 1971, Pis'ma Zh. Exp. Teor. Fiz. 14, 270 (1971); Zh. Exp. Teor. Fiz. 62, 2076 (1972).

Zouros, T. and Eardley, D. M.: 1979, Ann. Phys. (N.Y.) 118, 139.

\title{
БОЗЕОВА НЕСТАБИЛНОСТ У КЕРОВИМ ЦРНИМ РУПАМА
}

\author{
A. B. Gaina \\ ERGO.,2 Deleanu str., ap.146, Chişinău 277050, Republic of Moldova \\ УДК 524.882 \\ Оригинални научни рад
}

Бозеова нестабилност у ротирајућим (Керовим) црним рупама (ЦР) састоји се у експоненцијалном порасту у времену, малих пертурбација поља Бозеове масе, која одговарају суперрадијативним, квазивезаним нивоима. Минимално време пригушења угаоног момента 2P љуске је много мање него време пригушења угаоног момента суперрадијацијом, за примордијалне ЦР када је маса честица $m<<\frac{M_{P l}^{2}}{M}$. Веома брзо пригушење угаоног момента се дешава када је $0.46 \geq \frac{m M}{M_{P l}^{2}} \geq 0.203$ (за $\left.\pi^{0}\right), 0.353(\eta), .0 .065\left(D^{0}\right)$. Наелектрисана честица не може да развије Бозеову нестабилност услед јонизације везаних нивоа електромагнетним зрачењем које емитује сама ЦР.

Неутралне честице стварају $\gamma$-бљескове са енергијама $67.5,274.5,932 \mathrm{Mev}$ респективно. Трајање бљескова је $1.26 \cdot 10^{-17} \mathrm{~s}\left(\pi^{0}\right)$, $2.99 \cdot 10^{-18} \mathrm{~s}(\eta), 8.55 \cdot 10^{-19} \mathrm{~s}\left(D^{0}\right)$. Израчене енергије су $1.20 \cdot 10^{35} \mathrm{erg}, 8.67 \cdot 10^{34} \mathrm{erg}, 8.55$. $10^{33} \mathrm{erg}$, што одговара снагама реда величине $10^{52} \frac{\mathrm{erg}}{\mathrm{s}}$. Дискутоване су и друге последице испара̊̊вања црних рупа. 